\title{
Author Correction: Autophagic degradation of caveolin-1 promotes liver sinusoidal endothelial cells defenestration
}

Xiaoying Luo ${ }^{1,2}$, Dan Wang ${ }^{1,2}$, Xintao Zhu' ${ }^{1}$ Guozhen Wang ${ }^{2}$, Yuehua You' ${ }^{3}$ Zuowei Ning ${ }^{2}$, Yang Li , Siyi Jin², Yun Huang ${ }^{2}$, Ye Hu${ }^{2}$, Tingting Chen ${ }^{2}$, Ying Meng ${ }^{4}$ and $\mathrm{Xu} \mathrm{Li}^{1}$

\section{Correction to: Cell Death and Disease https://doi.org/10.1038/s41419-018-0567-0 published online 14 May 2019}

After publication of this article, it was realized that for the authors Xiaoying Luo, Dan Wang, Xintao Zhu and Xu Li the Nanfang Hospital at Southern Medical University was accidentally omitted from their affiliation designation. The correct full affiliation for the State Key Laboratory of Organ Failure Research is:
State Key Laboratory of Organ Failure Research, Guangdong Provincial Key Laboratory of Viral Hepatitis Research, Department of Infectious Diseases, Nanfang Hospital, Southern Medical University, Guangzhou, China. The authors apologize for this omission.

Published online: 17 June 2019

\footnotetext{
Correspondence: Ying Meng (519343749@qq.com) or

Xu Li (mylx99@smu.edu.cn)

'State Key Laboratory of Organ Failure Research, Guangdong Provincial Key Laboratory of Viral Hepatitis Research, Department of Infectious Diseases, Nanfang Hospital, Southern Medical University, Guangzhou, China ${ }^{2}$ Guangdong Provincial Key Laboratory of Gastroenterology, Department of Gastroenterology, Nanfang Hospital, Southern Medical University, Guangzhou, China

${ }^{3}$ Department of Stomatology, People's hospital of Longhua, Shenzhen, Guangdong, China

${ }^{4}$ Department of Respiratory Diseases, Nanfang Hospital, Southern Medical University, Guangzhou, China

These authors contributed equally: Xiaoying Luo, Dan Wang, Xintao Zhu

Edited by G.M. Fimia
}

(c) Open Access This article is licensed under a Creative Commons Attribution 4.0 International License, which permits use, sharing, adaptation, distribution and reproduction in any medium or format, as long as you give appropriate credit to the original author(s) and the source, provide a link to the Creative Commons license, and indicate if changes were made. The images or other third party material in this article are included in the article's Creative Commons license, unless indicated otherwise in a credit line to the material. If material is not included in the article's Creative Commons license and your intended use is not permitted by statutory regulation or exceeds the permitted use, you will need to obtain permission directly from the copyright holder. To view a copy of this license, visit http://creativecommons.org/licenses/by/4.0/. 